\title{
Combination Treatment for Extensive Chromoblastomycosis: A Case Report
}

\section{Dhan Keshar Khadka', Dipayan Pandey², Sudha Agrawal' ${ }^{1}$, Poonam Paudyal ${ }^{1}$, Basudha Khanal'}

${ }^{1}$ B.P. Koirala Institute of Health Sciences (BPKIHS), Dharan, Nepal; ${ }^{2}$ Association of Medical Doctors of Asia (AMDA), Damak, Nepal

\begin{abstract}
Chromoblastomycosis is a chronic and progressive recalcitrant fungal infection of the cutaneous and subcutaneous tissue caused by traumatic inoculation of a specific group of dematiacious fungi through skin. There are different treatment modalities for chromoblastomycosis (medical/surgical) having various efficacy. However, there is no treatment of choice for this disease. Though several therapeutic regimens have been proposed for almost 100 years, the disease may be recalcitrant and almost difficult to eradicate if diagnosed in later stage. Relapses are frequently reported. A combination of various treatment modalities is needed to achieve the best result.

We report here a case of chromoblastomycosis in a 62-year-male who presented with verrucous nodules and plaques on right lower limb. The patient was unresponsive to oral itraconazole $400 \mathrm{mg}$ daily for 2 months but was subsequently treated with multiple serial sittings of surgical excision and carbon dioxide laser in combination with oral itraconazole over 6 months. This case report focuses on proper management and specifically on differential diagnoses and treatment modalities for chromoblastomycosis.
\end{abstract}

Key words: Carbon dioxide laser; Chromoblastomycosis; Combination treatment.

\section{Introduction}

C hromoblastomycosis (CBM) is a chronic and progressive recalcitrant fungal infection of the cutaneous and subcutaneous tissue caused by dematiaceous fungi. ${ }^{1}$ It is an implantation mycosis mostly prevalent in the tropics and subtropics. Though major advancement has been made in the epidemiology and employment of molecular methods in the taxonomy of etiologic agent, there is less scientific progress in the management and this disease still represents a true therapeutic challenge for clinicians. ${ }^{2}$

Combination therapy with antifungal drugs are common part of regimen in severe and invasive

Funding: No

Conflict of Interest: No

\section{Address of Correspondence}

Dr. Dhan Keshar Khadka

ORCID ID: 0000-0002-3515-9623

Associate Professor, Department of Dermatology and Venereology

B.P. Koirala Institute of Health Sciences (BPKIHS), Dharan, Nepal Tel No.: 00977-25525555; Ext. No.: 2015;

Mob. No.: 00977-9842026086

E-mail: dhankesharjung@gmail.com infection. $^{3}$ Along with antifungal drugs, physical modalities of treatment like cryosurgery, simple surgical excision, local heat therapy or photodynamic therapy are also combined. Most of the reported cases have combined either antifungals or an antifungal and a chemotherapeutic agent or antifungal with one of the physical modalities mentioned above. Here, we have combined itraconazole monotherapy with simple surgical excision and Carbondioxide (CO2) laser assisted excision in a chronic and extensive lesion, which resulted in no recurrences and achieved significant clinical result which is burdensome in a deprived setting.

Date of Submission: $3^{\text {rd }}$ June 2021

Date of Acceptance: $26^{\text {th }}$ August 2021

Date of Publication: $1^{\text {st }}$ October 2021

How to cite this article

Khadka DK, Pandey D, Agrawal S, Paudyal P, Khanal B. Non-familial Combination Treatment for Extensive Chromoblastomycosis: A Case Report. NJDVL 2021;19(2):58-61. https://doi.org/10.3126/njdvl.v19i2.37543.

\section{(i)}

Licensed under CC BY 4.0 International License which permits use, distribution and reproduction in any medium, provided the original work is properly cited. 


\section{Case Report}

A 62-year male farmer presented to Dermatology Outpatient Department (OPD) with multiple, slow growing, mildly pruriginous, erythematous, verrucous plaques and nodules ranging in size from $2 \times 2 \mathrm{~cm}$ to $7 \times 8 \mathrm{~cm}$, oval to irregular in shape with well-defined border and rough surface extending from right midthigh to mid leg for last 10 years (Figure 1a). There was a significant history of cut injury during farming over right knee a week before beginning of these lesions. Majority of the lesions were discrete but few coalesced to form larger lesions. Most of the lesions were present linearly. Lesions were indurated, nontender with presence of peripheral semi-adherent scales. There was no local rise in temperature.

There was no history of chronic cough, weakness, weight loss, loss of appetite or evening rise of temperature. There was no history suggestive of tuberculosis in the family or neighbourhood. The clinical differential diagnoses of chromoblastomycosis, sporotrichosis and lupus vulgaris were made. The skin biopsies were sent for histopathology and tissue culture for fungus and AFB (Acid Fast Bacilli) stain for tuberculosis.

The routine haematological investigations were normal. Sputum for acid fast bacilli and Mantoux test were negative. Chest radiograph was normal. Incisional biopsy from periphery of the lesion

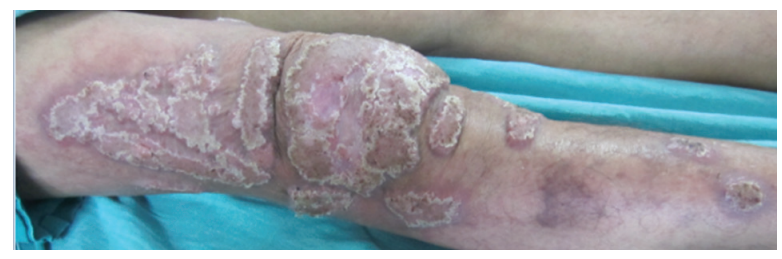

Figure 1a: Before treatment showing erythematous, verrucous plaques and nodules extending from right mid-thigh to mid leg

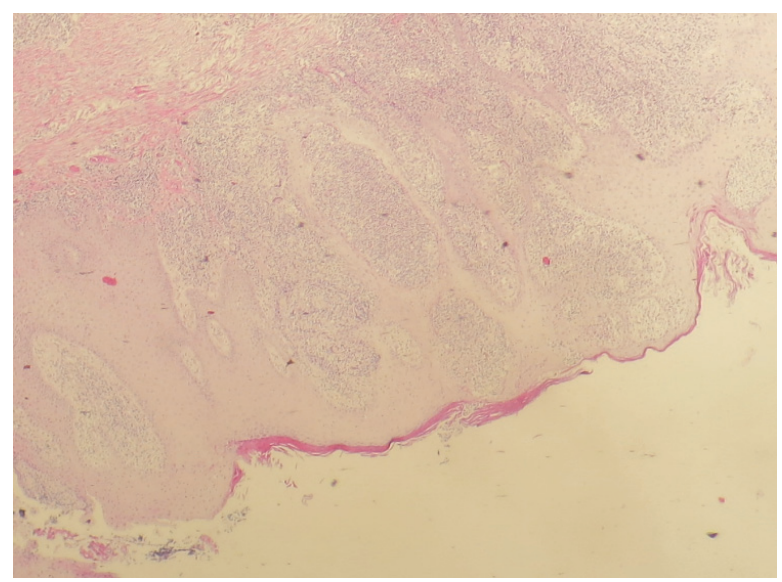

Figure 2a: Hyperkeratosis, epidermal hyperplasia, few intraepidermal neutrophilic abscess along with dense inflammatory infiltrates in upper dermis (Hematoxylin \& eosin, $\mathrm{X} 10$ ) showed hyperkeratosis, epidermal hyperplasia, few intraepidermal neutrophilic abscess along with dense inflammatory infiltrates in upper dermis (plasma cells, eosinophils, lymphocytes \& histiocytes.). Multinucleated Langerhans giant cells were seen throughout the dermis. Occasional oval/ spherical PAS positive thick-walled spores (Medlar bodies) were present within giant cells and in clusters of inflammatory cells (Figure 2). On tissue culture for fungal growth, Cladosporium species was grown after 4 weeks based on the colony characteristics. In tissue culture for Acid Fast Bacilli, there was no growth after 8 weeks, AFB was negative.

The findings were compatible with the diagnosis of chromoblastomycosis. The treatment with oral itraconazole (ITZ) 400mg daily was initiated but after two months there was not much clinical improvement. Monitoring of ITZ was done with Liver function test at baseline and at every 4 weeks of treatment. Then a few plaques and nodules were treated with ablative carbon dioxide laser with wavelength of $10600 \mathrm{~nm}$ and power of 9 to 15 Watt and surgical excision and ITZ was continued. Following CO2 laser, the raw skin surface was treated with topical mupirocin and gauze dressing. Total 7 sittings of $\mathrm{CO} 2$ laser were done and 9 smaller lesions were excised. By the end of 6 months, a significant clinical improvement of the lesion was observed (Fig 1 b) and no further development of the new lesions until 1-year post follow-up.

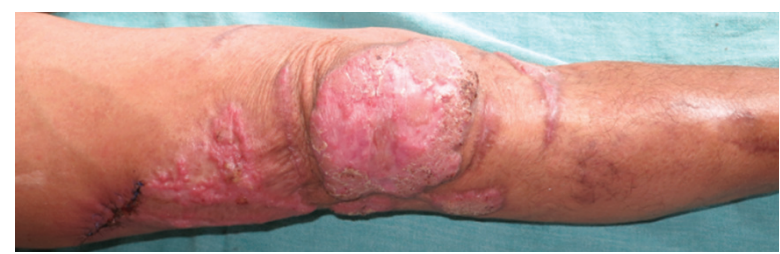

Figure 1b: Resolution of the initial lesion 6 months after treatment]

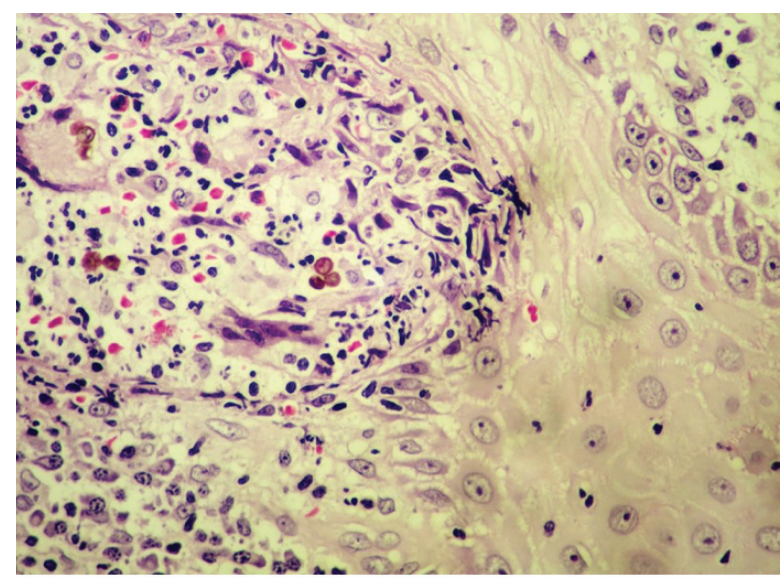

Figure 2b: showing Medlar bodies, few plasma cells, eosinophils, lymphocytes and histiocytes (Hematoxylin \& eosin, $\mathrm{X} 40$ ) 


\section{Discussion}

Chromoblastomycosis is a chronic infection caused by dematiaceous fungi affecting skin and subcutaneous tissue. ${ }^{4}$ The etiological agents mainly belong to three genera: Fonsecaea, Phialophora and Cladophialophora (Cladosporium) which are diagnosed by characteristic sclerotic or medlar bodies in tissue and the identification of the causal agent in culture. . $^{3,5-7}$

CBM lesions are clinically polymorphic and can mimic a wide spectrum of infectious diseases like cutaneous tuberculosis, sporotrichosis and non-infectious diseases like squamous cell carcinoma. There are five classically defined types of lesions: nodular, tumoral (cauliflower-like), verrucous, scarring, and plaque. In its more severe clinical forms, CBM produces fibrotic change and stasis of lymph causing lymphedema leading to secondary bacterial infection and inability to work.

There are different treatment modalities of chromoblastomycosis includes medical therapy (topical and systemic antifungal agents), physical methods (conventional surgery, thermotherapy, cryotherapy, LASERS, photodynamic therapy) or a combination of any of the above having various efficacy. $^{5,8}$ Chromoblastomycosis is a therapeutic challenge for the clinicians. There is no treatment of choice for this neglected mycosis.

According to several open and noncomparative clinical trials, Itraconazole(ITZ) at the dose of 200 to $400 \mathrm{mg} /$ day for adults is the standard therapy for CBM with cure rates range from 15 to $80 \%$.The duration of treatment varies; however, most cases show improvement within 8 to 10 months. ${ }^{9,10}$

\section{References}

1. Esterre P, Queiroz-Telles F. Management of chromoblastomycosis: novel perspectives. Curr Opin Infect Dis. 2006;19(2):148-52. doi: 10.1128/ CMR.00032-16

2. Agarwal R, Singh G, Ghosh A, Verma KK, Pandey $\mathrm{M}$, Xess I. Chromoblastomycosis in India: Review of 169 cases. PLoS Negl Trop Dis 2017; 11(8). DOI:10.1371/journal.pntd.0005534

3. Queiroz-Telles F, de CL Santos DW. Challenges in the Therapy of Chromoblastomycosis. Mycopathologia. 2013; 175:477-88.
Conventional surgery is considered one of the best physical method and is strongly recommended for all initial small and well-defined cutaneous lesions. Serial surgical excision may also be used in combination with ITZ or terbinafine treatment. There have been scattered reports of surgical removal of larger lesions in association with skin grafting, but there is a risk of dissemination of the infection. ${ }^{5}$

A CO2 laser has a very high precision, promotes photocoagulation, has minimal tissue damage, and hemostatic capacities. Due to its high continuous wave power, the carbon dioxide laser is an ideal and very useful nonselective ablative laser. Lasers have been applied both as monotherapy and in combination with other treatment modalities in the treatment of CBM. ${ }^{11-13}$ Other physical therapeutic methods may be helpful and consist of thermotherapy, cryotherapy and photodynamic therapy.

In our case, excision of smaller lesion using conventional surgery and $\mathrm{CO} 2$ laser helped us clearing up of lesion and prevented locally spreading of the lesion which was not responding to monotherapy of ITZ in the first two months of treatment. By the end of six months, a significant clinical improvement of lesions was observed with no further development of new lesions.

\section{Conclusion}

This case is being reported to emphasize that there are different treatment modalities for chromoblastomycosis (medical/surgical) having various efficacy. The combination of surgery/ $\mathrm{CO} 2$ laser and itraconazole may be the best treatment protocol, especially in cases of extensive disease.

4. Queiroz-Telles F, Santos DWC, Pedroso C. Fungal infections of implantation (chromoblastomycosis, mycetoma, entomophthoramycosis, and lacaziosis); Hospenthal D, Rinaldi MG; Diagnosis and treatment of fungal infections; $2^{\text {nd }}$ ed. 2015; Basel, Switzerland; 261-76

5. Queiroz-Telles F, de Hoog S, Santos DWCL, Salgado CG, Vicente VA, Bonifaz A, Roilides E et al.. Chromoblastomycosis. Clin Microbiol Rev 2017; 30: 233-76. DOI: https://doi.org/10.1128/ CMR.00032-16

6. Queiroz-Telles F, Nucci M, Colombo AL, Tobón A, Restrepo A. Mycoses of implantation in Latin America: an overview of epidemiology, clinical 
manifestations, diagnosis and treatment. Med Mycol. 2011; 49:225-36. https://doi.org/10.3109 /13693786.2010.539631

7. Bonifaz A, Vázquez-González D, PerusquíaOrtiz AM. Subcutaneous mycoses: chromoblastomycosis, sporotrichosis and mycetoma. J Dtsch Dermatol Ges. 2010; 8:619-27. DOI: 10.1111/j.1610-0387.2010.07453.x

8. Bonifaz A, Paredes-Solis V, Saul A. Treating chromoblastomycosis with systemic antifungals. A current review of physical and antifungal therapies for chromoblastomycosis. Expert Opin Pharmacother. 2004; 5:247-54. DOI: 10.1517/14656566.5.2.247

9. Queiroz-Telles F, Purim KS, Fillus JN, Bordignon GF, Lameira RP, Van Cutsem J et al. Itraconazole in the treatment of chromoblastomycosis due to Fonsecaea pedrosoi. Int J Dermatol. 1992; 31: 805-12. 10.1111/j.1365-4362.1992.tb04252.x.
10. Restrepo A, Gonzalez A, Gomez I, Arango M, de Bedout C. Treatment of chromoblastomycosis with itraconazole. Ann N Y Acad Sci. 1988; 544:504 -516. DOI: https://doi.org/10.1128/AAC.0027018

11. Hira K, Yamada H, Takahashi Y, Ogawa H. Successful treatment of chromomycosis using carbon dioxide laser associated with topical heat applications. J Eur Acad Dermatol Venereol. 2002; 16:273-75. DOI: 10.1046/j.1468-3083.2002.00479.x

12. Tsianakas A, Pappai D, Basoglu Y, Metze D, Tietz $\mathrm{HJ}$, Luger TA, et al. Chromomycosis successful $\mathrm{CO} 2$ laser vaporization. J Eur Acad Dermatol Venereol. 2008; 22:1385-86. doi: 10.1590/abd18064841.20187321

13. Kuttner BJ, Siegle RJ. Treatment of chromomycosis with a $\mathrm{CO} 2$ laser. J Dermatol Surg Oncol. 1986; 12:965-68. https://doi. org/10.1111/j.1524-4725.1986.tb02138.x 